\title{
Evaluation of the effectiveness of additional thermal insulation of the basement floor of frame-monolithic buildings in extreme operating conditions
}

\author{
Terentii Kornilov, Petr Fedotov, and Aleksandr Nikiforov \\ Engineering technical institute, North-Eastern Federal University named after M. K. Ammosov. \\ 677000 Yakutsk, 57, Belinskiy St., Russia.
}

\begin{abstract}
The issues of saving energy resources are of particular relevance for the regions of Russia with an extremely cold climate. The increased air pressure difference in winter and the presence of volumetric cold bridges in the form of pile and column grillages, basement slabs and concrete block masonry often leads to a violation of the temperature regime of the first floors of multi-storey buildings with a monolithic reinforced concrete frame. Thermal analysis of fragments of basement floors in areas with columns and grillages with additional thermal insulation from the outside was carried out. The low efficiency of the external thermal insulation of the basement elements of the operated frame-monolithic buildings is shown.
\end{abstract}

\section{Introduction}

The main global trend in construction is to improve the energy efficiency of buildings and reduce energy consumption for their operation. The residential sector in Russia ranks second in terms of final energy consumption: $25 \%$ of the current energy consumption in general and $45 \%$ of thermal energy consumption [1]. As a result of the implementation of state program measures to improve the energy efficiency of the housing sector, Russia has significantly improved its position in the ranking among countries for the implementation of energy efficiency policies [2]. For the Republic of Sakha (Yakutia), the issues of saving energy resources are of particular relevance, since, according to climatic conditions, Yakutia is the coldest vast territory in the world, where there is a negative average annual temperature. The duration of the heating period for residential buildings on the territory of Yakutia is 250 days in the southern regions and more than 300 days in the Arctic regions at an average annual outside air temperature of $-13.6^{\circ} \mathrm{C} \ldots-25.3^{\circ} \mathrm{C}$.

Losses of thermal energy through external enclosing structures are the main ones and account for more than $50 \%$ in the structure of thermal energy consumption of a building for heating during the heating period [3]. In this regard, in the regulatory documents on thermal protection of European countries and Russia, the normalized values of the reduced resistance to heat transfer of enclosing structures have been significantly increased [4,5]. For example, for the climatic conditions of Yakutia, very high values of the reduced 
resistance of the walls of residential multi-storey buildings are regulated, 4.61-5.75 $\left(\mathrm{m} 2{ }^{\circ} \mathrm{C}\right) / \mathrm{W}$ and basement ceilings over the ventilated underground $6.77-8.41\left(\mathrm{~m} 2^{\circ} \mathrm{C}\right) / \mathrm{W}$. For a qualitative assessment of the thermal protection of enclosing structures, an engineering method was developed for calculating the reduced resistance to heat transfer, taking into account heat-conducting inhomogeneities, which is included in SP 230.1325800.2015 Enclosing structures of buildings. Characteristics of heat engineering heterogeneities [6-8]. In the Russian system for standardizing the thermal protection of buildings, the increase in requirements for the energy efficiency of buildings is carried out not only by increasing the required values of the reduced resistance to heat transfer of enclosing structures, but also by standardizing the specific thermal characteristics of a building [4].

In recent decades, on the territory of the Republic of Sakha (Yakutia), intensive construction of multi-storey residential buildings has been carried out, and in terms of the area of housing commissioned annually, the republic occupies a leading position in the Far East. According to the results of the analysis of the sites and project declarations of developers for October 2020, 37 houses under construction by developers were identified in the territory of the republic. Of these, 32 houses have a monolithic reinforced concrete frame, 24 units have 13-17 floors. The increase in the number of storeys in buildings under construction (13 floors and more) is associated with the possibility of using the technology of monolithic housing construction in permafrost conditions. In frame-monolithic buildings, there are a number of problems associated with the presence of cold bridges. In [9], devices for additional insulation of the junction points of the outer wall with the interfloor reinforced concrete ceiling are proposed, and as a result of heat engineering studies, their effectiveness is shown. For protruding elements - balcony slabs of framemonolithic buildings, the rationale for the use of load-bearing heat-insulating elements is given in $[10,11]$. One of the problematic "cold bridges" is the conjugation of concrete block masonry with a basement reinforced concrete floor. In $[12,13]$, it is proposed to improve the thermal protection in these areas by using thermal inserts or beams on supports.

As a result of the examination and operation of apartment buildings in Yakutsk, it was found that on the inner surface of the basement floor of sections with columns, a low temperature is most often observed that does not meet regulatory requirements [14]. The main reason for the violation of the thermal protection of the first floor of frame buildings with pile foundations is the presence of volumetric cold bridges: reinforced concrete grillage - basement ceiling - columns - walls made of concrete blocks. In these areas, it is difficult to exclude "cold bridges" from supporting structures by constructive methods. At the same time, the high height of buildings and the extremely low temperature of the outside air cause an increased difference in gravitational pressure, which leads to intensive penetration of cold air through small leaks in the mating of external fences elements. In the operating conditions of buildings, one of the most possible options for improving the temperature regime of the first floors of frame-monolithic buildings is partial external thermal insulation of the basement floor and grillages. This article provides a thermal analysis of these design measures.

\section{Methods}

In frame-monolithic buildings under construction in Yakutsk, the construction of external walls with a masonry base using small concrete blocks with $\gamma=1800 \mathrm{~kg} / \mathrm{m} 3$ in accordance with all-Union State Standard 6133-99 is most often used, to which mineral wool slabs with a density of $125 \mathrm{~kg} / \mathrm{m} 3200 \mathrm{~mm}$ thick and ventilated façade elements. The basement floor consists of a monolithic reinforced concrete slab with a thickness of $220 \mathrm{~mm}$, an insulating layer of expanded polystyrene plates with a density of $35 \mathrm{~kg} / \mathrm{m} 3$ and a thickness of 300 $\mathrm{mm}$, a cement-sand screed $60 \mathrm{~mm}$ thick and a leveling layer $20 \mathrm{~mm}$ thick. Columns of the 
first floor in frame-monolithic buildings are accepted according to the project with a section of $600 \times 600 \mathrm{~mm}$ or $400 \times 900 \mathrm{~mm}$. Under each column of the first floor of 9-16-storey buildings in permafrost conditions, $2-4$ piles connected by a reinforced concrete grillage are installed.

Thermal analysis of basement floors fragments in sections with columns was carried out using the certified "HEAD 3D" software for three-dimensional modeling of stationary and non-stationary heat transfer processes. The program allows you to model any enclosing structure consisting of bordering or overlapping rectangles with any combination of materials. Boundary conditions can be specified by heat flux or temperature with surface resistance. Temperatures and heat fluxes can change over time.

When conducting a thermal analysis, the design temperatures of the outside and inside air were taken respectively $\mathrm{tH}_{\mathrm{H}}=-52.0^{\circ} \mathrm{C}$ and $\mathrm{tB}_{\mathrm{B}}=+21.0^{\circ} \mathrm{C}$. Characteristics of the enclosing structures materials: thermal conductivity coefficient $\lambda=1.92 \mathrm{~W} /\left(\mathrm{m}^{\circ} \mathrm{C}\right)$ for reinforced concrete basement slabs, columns and grillages; $\lambda=0.042 \mathrm{~W} /\left(\mathrm{m}^{\circ} \mathrm{C}\right)$ for polystyrene foam board PSB-S $35 ; \lambda=0.76 \mathrm{~W} /\left(\mathrm{m}^{\circ} \mathrm{C}\right)$ for cement-sand screed and leveling layer; $\lambda=0.64$ $\mathrm{W} /\left(\mathrm{m}^{\circ} \mathrm{C}\right)$ for wall stone masonry on cement-sand mortar; $\lambda=0.042 \mathrm{~W} /\left(\mathrm{m}^{\circ} \mathrm{C}\right)$ for mineral wool boards.

\section{Results}

Unit 1 of the junction of the outer wall to the basement floor. This unit has a cold bridge: a reinforced concrete basement ceiling - masonry made of small concrete blocks. To reduce the effect of the cold bridge, the designers propose additional thermal insulation of protruding beams and ceilings from the outside using P125 mineral wool plates with a thickness of $200 \mathrm{~mm}$. The slab thermal insulation is provided in the area along the outer walls with a width of $1200 \mathrm{~mm}$. The design model of the junction of the outer wall to the ceiling is shown in Fig. 1, a. The results of the thermal engineering calculation show that the minimum temperature on the inner surface of the fence after additional thermal insulation is observed in the corner between the masonry and the cement-sand screed (Fig. $1, b)$ and is $\operatorname{tmin}=+13.2^{\circ} \mathrm{C}$, which is higher than the dew point temperature $\left(\mathrm{tp}=+12.9^{\circ} \mathrm{C}\right)$. At the same time, the minimum temperature does not correspond to the standardized temperature difference between the temperature of the internal air and the temperature of the internal surface of the enclosing structure $\left(\Delta \mathrm{tn}=2.0^{\circ} \mathrm{C}\right)$. The minimum temperature on the inner surface is $2.54^{\circ} \mathrm{C}$ higher than that of the existing unit. A positive point is some displacement of the line with zero temperature to the outside, which is located at a distance of $100 \mathrm{~mm}$ from the angle between the screed and the outer wall (Fig. 1, table 1).

Table 1. Thermal characteristics of units

\begin{tabular}{|c|c|c|c|c|}
\hline $\begin{array}{c}\text { Unit } \\
\text { № }\end{array}$ & Type & $\begin{array}{c}\text { The minimum } \\
\text { temperature on the inner } \\
\text { surface }\left[{ }^{\circ} \mathrm{C}\right]\end{array}$ & $\begin{array}{c}\text { Distance from inner corner } \\
\text { to zero temperature line } \\
{[\mathrm{mm}]}\end{array}$ & $\begin{array}{c}\text { Heat loss } \\
\text { through the unit } \\
{[\mathrm{W} / \mathrm{m}]}\end{array}$ \\
\hline \multirow{2}{*}{1} & Existing & $+10,66$ & 80 & 64,98 \\
\cline { 2 - 5 } & $\begin{array}{c}\text { After thermal } \\
\text { insulation }\end{array}$ & $+13,2^{\circ} \mathrm{C}$ & 100 & 53,44 \\
\hline \multirow{2}{*}{2} & Existing & $+6,1$ & 50 & 169,78 \\
\cline { 2 - 5 } & $\begin{array}{c}\text { After thermal } \\
\text { insulation }\end{array}$ & $+8,0$ & 90 & 150,06 \\
\hline \multirow{2}{*}{3} & Existing & $+6,22$ & 70 & 408,84 \\
\cline { 2 - 5 } & $\begin{array}{c}\text { After thermal } \\
\text { insulation }\end{array}$ & $+6,73$ & 80 & 329,7 \\
\hline
\end{tabular}


a.

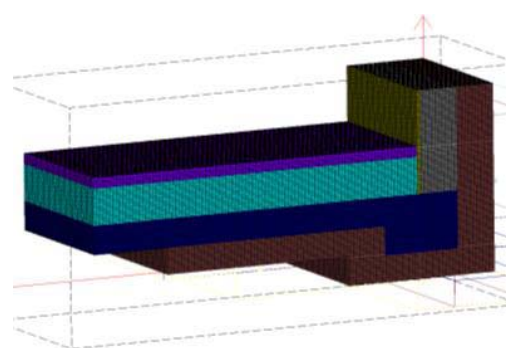

b.

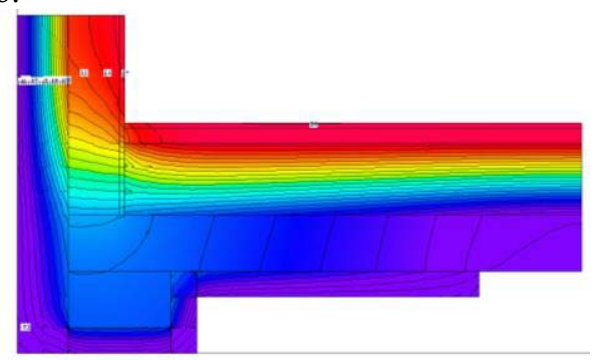

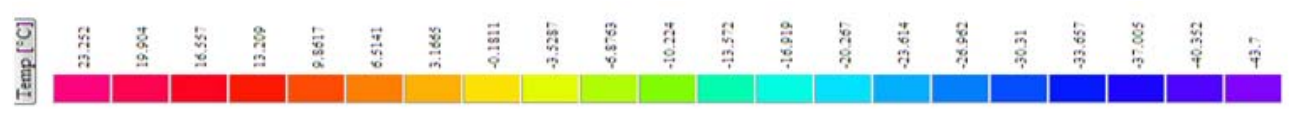

Fig. 1. The results of the heat engineering calculation of unit $1: \mathrm{a}$ - design model; $\mathrm{b}$ - temperature field in vertical section

a.

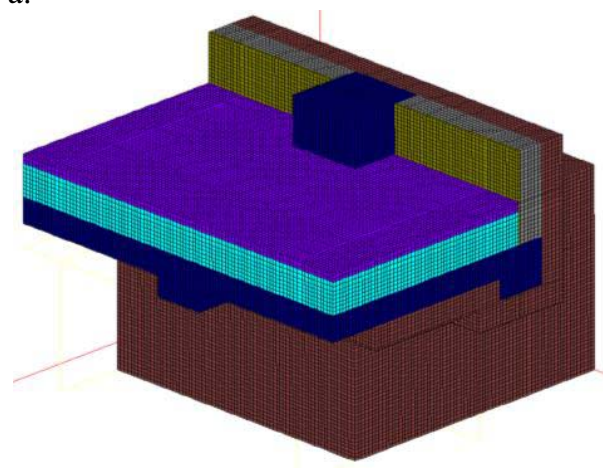

c.
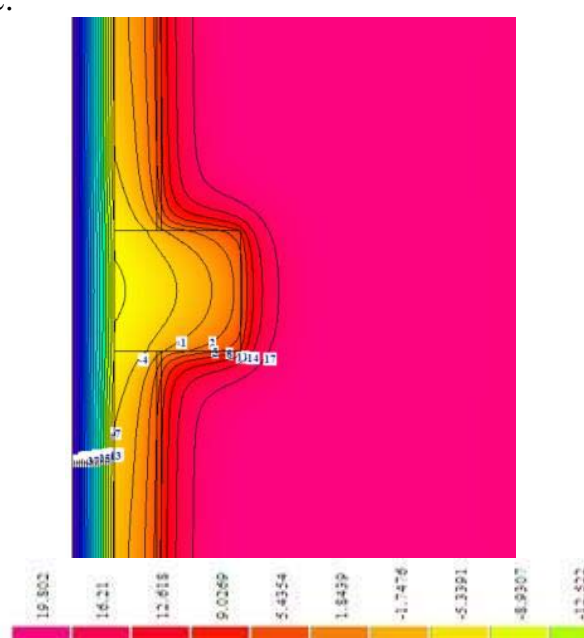

b.

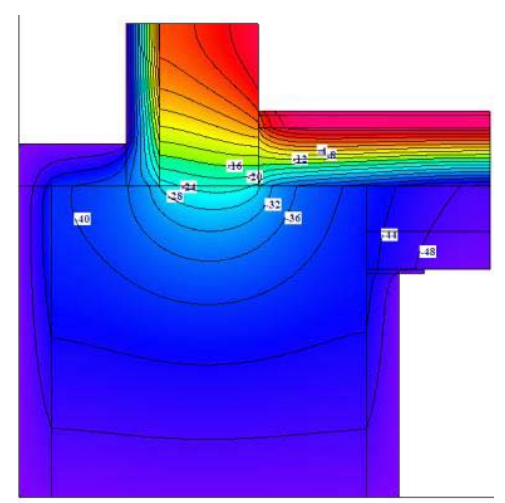

d.

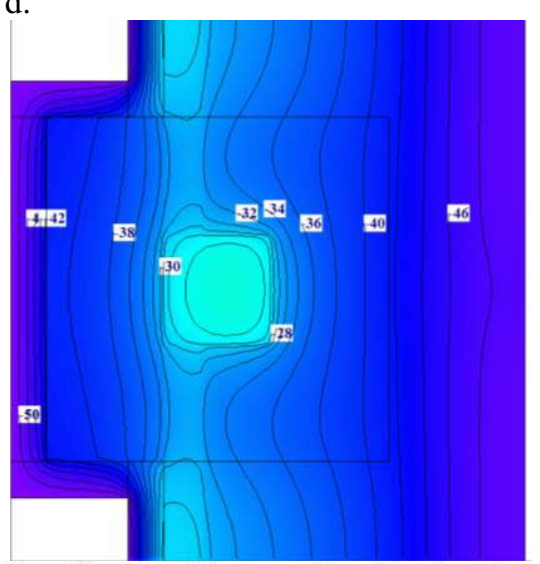

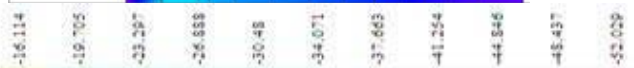

Fig. 2. Results of heat engineering calculation of unit 2: a - design model; $b$ - temperature field in a vertical section along the column wall; $\mathrm{c}$ - in a horizontal section along the smooth surface of the floor; $\mathrm{d}$ - in a horizontal section along the smooth surface of the basement slab 
a.

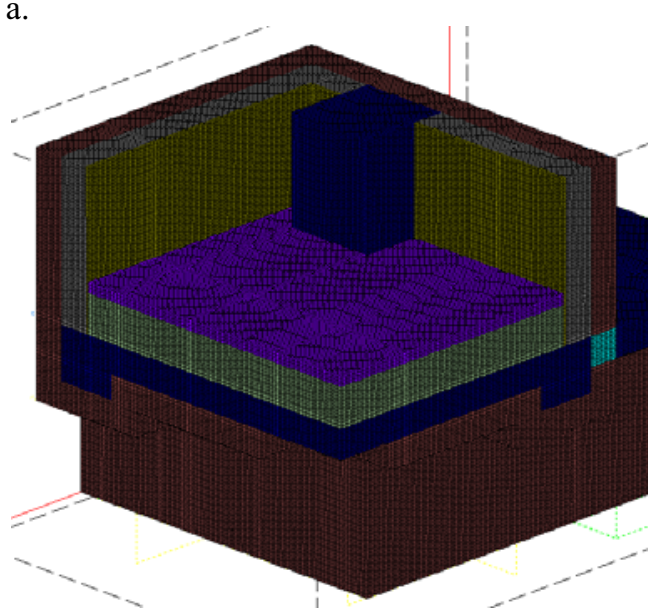

c.

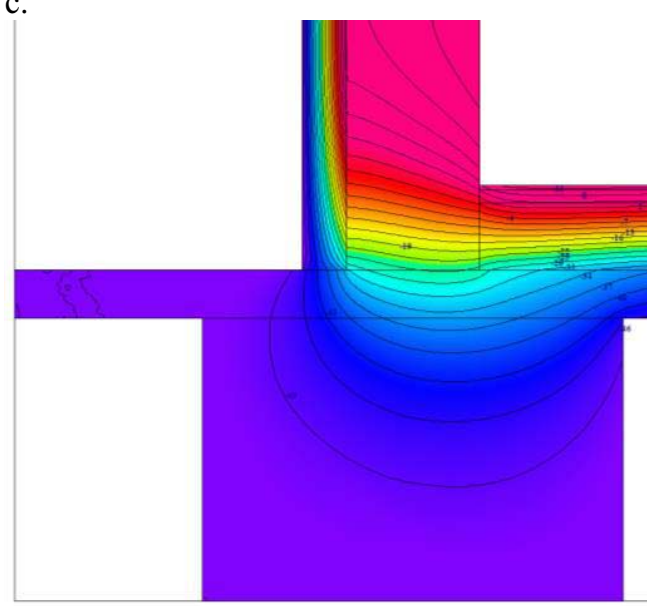

b.

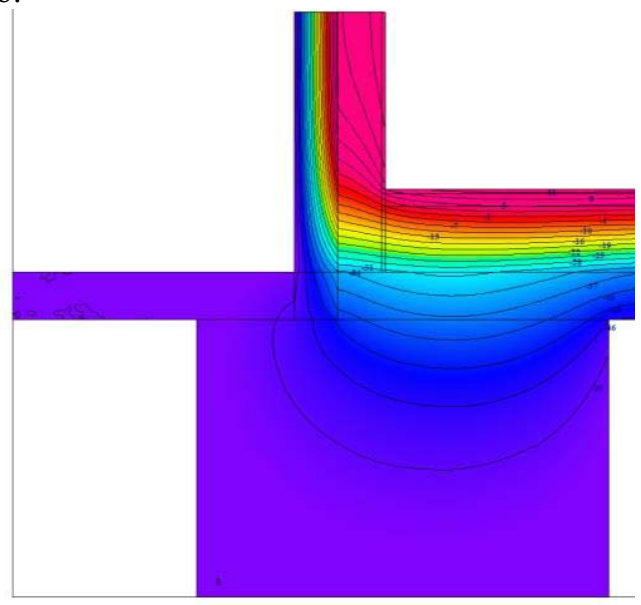

d.

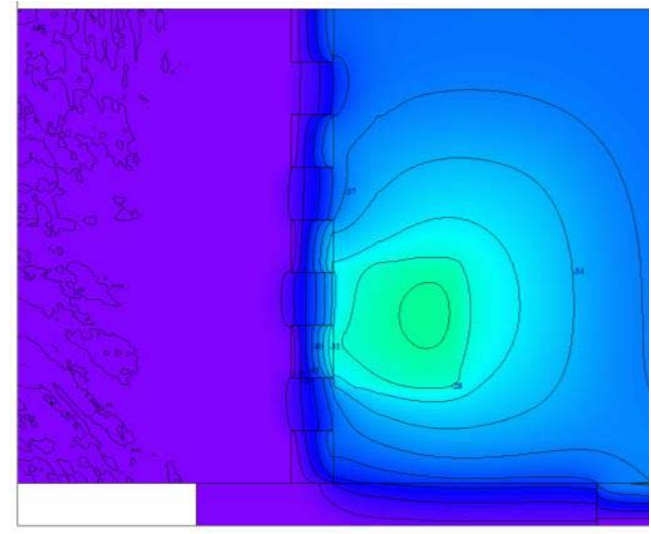

Fig. 3. Results of heat engineering calculation of unit 3: a - design model; b - temperature field in a vertical section along the inner surface of the left wall; $\mathrm{c}$ - in a vertical section along the surface of the column from the side of the left wall; $\mathrm{d}$ - in a horizontal section along the smooth surface of the basement

Unit 2 of the junction of the outer wall to the basement ceiling with a column. In this section of the basement floor, there is a reinforced concrete column with a cross section of $600 \times 600 \mathrm{~mm}$ with a grillage between piles with dimensions in plan $1900 \times 1900 \mathrm{~mm}$ and a height of $1280 \mathrm{~mm}$. The accepted constructive solution of the basement floor section has volumetric "cold bridges": reinforced concrete grillage - column - floor slab - masonry of small concrete stones. Consider a possible option for external thermal insulation using P125 mineral wool slabs with a thickness of $200 \mathrm{~mm}$ on the surface of a reinforced concrete grillage along the perimeter and on top. Additional thermal insulation of beams and floors is the same as in the previous unit.

The design model of the basement section with the column and the results of the heat engineering calculation are shown in Fig. 2. The minimum temperature on the floor surface occurs in the corner between the column and the outer wall and is tmin $=+8.0^{\circ} \mathrm{C}$, which is significantly lower than the dew point temperature (Fig. 2, c). Compared to the existing unit, the minimum temperature on the inner surface of the enclosing structure increases by 
$1.9^{\circ} \mathrm{C}$. In this case, the line with zero temperature in the considered joint is practically under the cement-sand screed at a distance of $90 \mathrm{~mm}$ from the corner (Fig. 2, Table 1).

Unit 3 walls with a column in the corner of the building. The considered section of a monolithic frame building is limited by three cold spaces and, as a rule, is the coldest. In the area under consideration, one outer wall is located on the cantilever part of the basement floor and is slightly offset from the column. Here, to the above-mentioned cold bridges, a protrusion of the basement ceiling is added - a balcony slab, although there is a perforation between the balcony slab and the main ceiling. The computational model of a fragment of a basement floor with a corner column is shown in Fig. 3, a.

The minimum temperature is observed in 2 areas along the floor surface: in the corner between two perpendicular outer walls and the corner between the right outer wall and the column. At the same time, the minimum temperature on the inner surface increases by only $0.51^{\circ} \mathrm{C}$ compared to the existing one and is tmin $=+6.73^{\circ} \mathrm{C}$ (Fig. 3), which is significantly lower than the dew point temperature $\left(\mathrm{t} p=+12.9^{\circ} \mathrm{C}\right)$. Also, no displacement of the line with zero temperature in the unit under consideration after additional thermal insulation is observed and this isotherm is practically located in the corner under the cement-sand screed (Fig. 3, b, c). From Fig. 3 d, e, the location of the isothermal lines clearly shows the influence of cold bridges: a balcony slab and a column with a grillage.

\section{Conclusion}

As a result of the thermal analysis of problem areas of the basement floor of framemonolithic buildings after additional thermal insulation in extreme operating conditions $\left(\mathrm{tH}=-52^{\circ} \mathrm{C}\right)$, the following conclusions were made:

In an ordinary junction of the outer wall with the basement floor, the use of external thermal insulation of the beams and the floor area is very effective. The temperature on the inner surface of the floor rises to $+13.2^{\circ} \mathrm{C}$, heat losses decrease by $17.7 \%$, the line with zero temperature shifts outward from the inner corner to $100 \mathrm{~mm}$.

In the areas of the basement floor with columns, additional thermal insulation of the surface of the reinforced concrete grillage does not lead to a significant increase in the thermal protection of the enclosing structures fragments. The minimum temperature on the inner surface of the considered fragments of the basement floor with columns is significantly lower than the dew point temperature. A massive reinforced concrete grillage has an extremely negative effect on the temperature distribution inside the structure and causes the line with zero temperature to be located in the corner zones close to the floor surface. In these sections with columns, a new constructive solution is required with a cut of the grillage from the basement with a thermal insert.

\section{References}

1. A.S. Gorshkov, Energy efficiency in construction: issues of regulation and measures to reduce the energy consumption of buildings, Engineering and construction journal, 1, Pp. 9-13 (2010)

2. S.G. Sheina, N.P. Umnyakova, P.V. Fedyaeva, E.N. Minenko, The best European experience in the implementation of energy-saving technologies in the housing stock of the Russian Federation, Housing construction, 6, Pp. 29-34 (2020)

3. N.I. Vatin, D.V. Nemova, P.P. Rymkevich, A.S. Gorshkov, Influence of the level of thermal protection of enclosing structures on the amount of heat energy losses in a building, Engineering Journal, 8 (34). Pp. 21-27 (2012) 
4. V.G. Gagarin, A.Yu. Neklyudov, Prospects for the use of the updated edition of Building regulations "Thermal protection of buildings" to reduce heat losses through the enclosing structures. ALITinform: Cement. Concrete. Dry mixes. 6 (41). Pp. 80-87 (2015)

5. M. Citterio, M. Cocco, H. Erhorn-Kluttig, Thermal bridges in the EBPD context: overview on MS approaches in regulations. EBPD Buildings Platform, 28(4), 64 (2008)

6. V.G. Gagarin, V.V. Kozlov, Theoretical preconditions for calculating the reduced resistance to heat transfer of enclosing structures, Construction materials, 12. Pp. 4-12 (2010)

7. V.G. Gagarin, K.A. Dmitriev, Accounting for thermal engineering inhomogeneities in the assessment of thermal protection of enclosing structures in Russia and European countries, Construction Materials, 6, Pp.14-16 (2013)

8. V.G. Gagarin, A.Yu. Nelyudov, Application of the methodology for accounting for thermal inhomogeneities of enclosing structures from the updated version of the Building regulations "Thermal protection of buildings" for calculating the load on heating and cooling systems of buildings, Engineering systems. AVOK - North-West, 2, 10 (2015)

9. A.V. Kuznetsov, Units insulation of the walls conjugation with a floor disc in monolithic houses, Housing construction, 8. Pp.32-34 (2013)

10. N.P. Umnyakova, K.S. Andreitseva, V.A. Smirnov, Heat transfer on the surface of protruding elements of external fencing, News of higher educational institutions. Textile industry technology, 4 (364), Pp. 157-161 (2016)

11. N.P. Umnyakova, T.S. Egorova, K.S. Andreitseva, V.A. Smirnov, V.A. Lobanov, New constructive solution of conjugated external walls with monolithic interfloor ceilings and balcony slabs, Construction Materials, 6, Pp. 28-31 (2013

12. T.A. Kornilov, I.R. Kychkin, O.N. Ovchinnikova, Improving the thermal protection of the basement floor of frame-monolithic buildings with ventilated undergrounds, Construction and reconstruction, 3 (71), Pp. 58-67 (2017)

13. N.D. Danilov, A.A. Sobakin, P.A. Fedotov, Optimal insulation of the frame-monolithic buildings walls joint with ventilated undergrounds, Housing construction, 6, Pp. 28- 31 (2016)

14. T.A. Kornilov, I.R. Kychkin, E.G. Slobodchikov, Problems of a thermal insulation of multystoried cast-in-place concrete frame buildings in the conditions of Extreme North, IOP Conference Series: Materials Science and Engineering, 463, 032004, (2018) 